\title{
A METHOD FOR HOST RANGE TESTING OF A BIOLOGICAL CONTROL AGENT FOR URABA LUGENS
}

\author{
L.A. BERNDT ${ }^{1}$, S. MANSFIELD ${ }^{2}$ and T.M. WITHERS ${ }^{1}$ \\ ${ }^{1}$ Ensis Forest Biosecurity and Protection, PO Box 3020, Rotorua, New Zealand \\ ${ }^{2}$ Faculty of Agriculture, Food and Natural Resources, University of Sydney, \\ NSW 2006, Australia
}

Corresponding author: lisa.berndt@ensisjv.com

\begin{abstract}
Uraba lugens (gum leaf skeletoniser) is a serious pest of Eucalyptus spp. in Australia. It is now well established in the greater Auckland region, and is spreading. Two parasitoid species are under consideration as potential biological control agents of $U$. lugens. This paper describes host range testing methods developed using one of these species (Cotesia urabae) against two non-target species, Helicoverpa armigera and Spodoptera litura. Using sequential no-choice tests to test the response of mated C. urabae females, clear preferences were observed for $U$. lugens over both non-target test species. Some females did attempt to attack the non-target species, but no evidence of parasitism was observed when non-target hosts were reared or dissected. This method elucidated both behavioural responses and physiological development of $C$. urabae, and it is proposed to be a suitable host range testing method for full evaluation of this species.
\end{abstract}

Keywords: classical biological control, sequential no-choice test, parasitoid, Braconidae, Lepidoptera.

\section{INTRODUCTION}

Eucalyptus trees nationwide are under serious threat from Uraba lugens Walker (Lepidoptera: Nolidae; gum leaf skeletoniser) a significant pest of eucalypts in its native Australia. This pest was first found in Mt Maunganui in 1992, but was eradicated from that location. Another population was found in Auckland in 2001, and this continues to spread, threatening eucalypt plantations and amenity trees over much of the country (Berndt 2007). Research into biological control of $U$. lugens is underway, and permission was obtained in 2004 to import four Australian parasitoid species into quarantine in New Zealand for further study (Mansfield et al 2005). Two of these species (Cotesia urabae Austin \& Allen and Dolichogenidea eucalypti Austin \& Allen (both Hymenoptera: Braconidae)) have been reared in containment and remain in contention as potential biological control agents (Berndt 2007). These species are solitary larval endoparasitoids in the subfamily Microgastrinae, preferentially attacking gregarious 1-5th instar U. lugens larvae (Allen 1990).

A list of lepidopteran species appropriate for host range testing of potential $U$. lugens biological control agents includes Celama parvitis (Howes) (Nolidae), the only New Zealand endemic in the same family as $U$. lugens, as well as representatives of the related family Arctiidae (Withers 2003; Mansfield et al. 2005). Two species of Noctuidae, the pests Helicoverpa armigera (Hübner) and Spodoptera litura (F.), are also included as U. lugens was previously placed in this family (Withers 2003).

There is ongoing debate over what methods are appropriate to determine host range for arthropod biological control, and the biology of the agent and hosts must be taken into account in test design (Van Driesche \& Murray 2004). No-choice test designs are currently favoured, with the parallel no-choice test format the most widely used (Barratt 
2004; Withers \& Mansfield 2005). In such a design, one replicate consists of parasitoids, randomly assigned to either target or non-target host. Initial observations of $C$. urabae indicated that $40 \%$ of females were not motivated to attack host larvae within an hour of exposure (L.A. Berndt, unpubl. data). Therefore the parallel no-choice test format would require high replication to overcome this known high variability in female responsiveness to hosts. Because the number of mated female $C$. urabae available for experiments was low, and many non-target species are difficult to obtain in large numbers (Mansfield et al. 2005), a more economical method was required.

A sequential no-choice design with an A-B-A sequence (where $\mathrm{A}$ is the target host and $\mathrm{B}$ is the non-target host) is described here, using $C$. urabae against the non-target species $H$. armigera and S. litura as a model. This method is controversial due to the potential confounding effects of time-dependent and experience-induced changes in parasitoid responsiveness to hosts (Barton Browne \& Withers 2002; Withers \& Mansfield 2005). However, the A-B-A sequential no-choice design openly controls for (and effectively excludes) those female parasitoids that for unknown reasons are not motivated to attack hosts. Therefore this design is more economical with rare parasitoids and hosts than the more widely used parallel no-choice test formats.

\section{METHODS}

Cotesia urabae were reared from $U$. lugens larvae collected in Hobart, Tasmania, Australia, in November and December 2006. Parasitoid cocoons were shipped to the Ensis quarantine facility in Rotorua on 12 December 2006. The C. urabae colony was maintained on second to fourth instar $U$. lugens larvae reared on Eucalyptus nitens. Nontarget larvae (H. armigera and S. litura) were reared in individual pottles on pinto bean diet (supplied by HortResearch, Auckland). Experiments were conducted in quarantine at $20^{\circ} \mathrm{C}, 65 \% \mathrm{RH}$, and a $14: 10 \mathrm{~h}$ light:dark regime. Sequential no-choice experiments were conducted between 19 and 27 January 2007 using mated female C. urabae (1-4 days old) from the F1 generation.

One replicate consisted of one female parasitoid observed on target and non-target hosts in experimental arenas using an A-B-A sequence. Between six and eight replicates were conducted for each non-target species. A maximum of two replicates could be observed simultaneously, along with one negative control with host larvae but no parasitoids. Parasitoids were enclosed initially with the target host for 10 minutes (A1), then moved on to the non-target host for 24 hours (B), before being moved to another set of target hosts for 10 minutes (A2). Observations were made of parasitoid behaviour on each set of hosts.

Experimental arenas were $100 \mathrm{~mm}$ diameter glass Petri dishes, each with a piece of foliage, E. nitens for U. lugens, silverbeet (Beta vulgaris var. cicla) for S. litura, or clover (Trifolium repens) for $H$. armigera. The silverbeet and clover also had a ca $10 \mathrm{~mm}$ cube of pinto bean diet on the foliage, which was added as additional food for non-target larvae, because the non-target food plants desiccated quickly. Ten second or third instar $U$. lugens larvae were added to E. nitens in $\mathrm{A} 1$ and $\mathrm{A} 2$ arenas, and 10 non-target hosts of a similar physical size $(3-10 \mathrm{~mm})$ were added to the appropriate foliage in B arenas prior to the start of observations.

Each parasitoid was observed attacking target hosts for 10 minutes (A1 arena), then moved to a non-target B arena and observed for two consecutive 10 minute periods (B1 and B2). Parasitoids were then left in the non-target B arena for 24 hours before another observation of two consecutive 10 minute periods (B3 and B4). At the end of these observations, parasitoids were moved to new target hosts (A2 arena) and observed for a further $10 \mathrm{~min}$. Behavioural observations and the $\mathrm{A} 1$ period began once the parasitoid first attacked the target host larvae. To eliminate parasitoids that were not ready to attack larvae, those that did not show interest in the target hosts (A1) within $30 \mathrm{~min}$ were excluded.

Behavioural observations consisted of total frequencies of the number of times parasitoids approached larvae, probed, and attacked larvae. Larval approach consisted 
of the parasitoid moving close enough to a larva to touch it with its antennae. Probing behaviour consisted of the parasitoid stabbing with its ovipositor but not contacting a larva with it. Larval attack was recorded when the parasitoid successfully stabbed a larva with its ovipositor. Behavioural data were analysed using a log-linear model (GENMOD procedure, SAS Version 8.2). After the completion of the observations, target and non-target larvae were reared to parasitoid development or pupation. Three weeks after completion of the experiments, five non-target larvae from each replicate were frozen, dissected and examined for evidence of parasitoid attack at $8 \times, 25 \times$ and $50 \times$ magnification. Mortality of non-target larvae was analysed using Wilcoxon signed-rank test (NPAR1WAY procedure, SAS Version 8.2).

\section{RESULTS AND DISCUSSION}

In sequential no-choice tests, $C$. urabae approached $U$. lugens larvae significantly more than they did non-target larvae $(\mathrm{P}<0.005$, Fig. 1). No instances of probing behaviour were observed in response to non-target species, although this was a common behavioural response to $U$. lugens larvae and larval feeding damage on eucalypt leaves (Fig. 1). Larval attack behaviour was observed on both $S$. litura and $H$. armigera larvae, however the incidence of this was significantly lower than on U. lugens $(\mathrm{P}<0.0001$, Fig. 1). Parasitoids

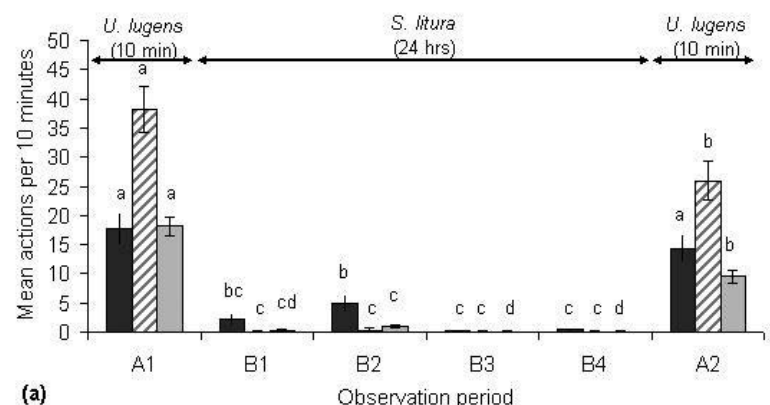

(a)

Observation period

- Approach larva $\square$ Probe $\square$ Attack larva

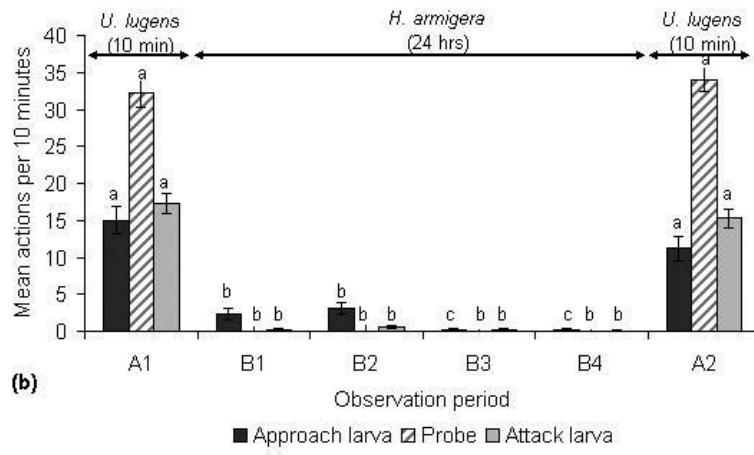

FIGURE 1: Mean $( \pm$ SE) number of larval approaches, probes and larval attacks by Cotesia urabae on target (Uraba lugens) and non-target (a) Spodoptera litura, (b) Helicoverpa armigera larvae. Values are the mean per $10 \mathrm{~min}$ observation period in A-B-A sequential no-choice tests. Bars of one behaviour type sharing a letter do not differ significantly at $\mathbf{P}<0.05$. Means are back transformed. 
that did attack non-target species tended to attack larvae that were roaming the arena and that spun down when encountered, ignoring those settled on the leaf or remaining motionless on encounter. This contrasted strongly with attack behaviour on $U$. lugens, where parasitoids repeatedly visited the leaf to attack the cluster of larvae. No evidence of parasitoid attack was found in either non-target species from rearing or dissection, compared to $U$. lugens parasitism of 65 to $92 \%$ (Table 1 ).

TABLE 1: Parasitism (\%) of Uraba lugens and non-target (Spodoptera litura and Helicoverpa armigera) larvae by Cotesia urabae in A-B-A sequential no-choice tests. Also shown is the mean number of unexplained deaths among non-target larvae. Ten larvae were exposed to each parasitoid in each arena per replicate, $\mathbf{n}=$ number of replicates.

Mean \pm SE parasitism ${ }^{1}$ in no choice tests

(n)
Mean \pm SE unexplained

deaths among non-target

larvae (n)

\begin{tabular}{lcccccc}
\cline { 2 - 3 } $\begin{array}{l}\text { Non-target } \\
\text { species }\end{array}$ & $\begin{array}{c}\text { U. lugens } \\
(\mathrm{A} 1)(10 \mathrm{~min})\end{array}$ & $\begin{array}{c}\text { Non-target } \\
(\mathrm{B})(24 \mathrm{hr})\end{array}$ & $\begin{array}{c}\text { U. lugens } \\
(\mathrm{A} 2)(10 \mathrm{~min})\end{array}$ & $\begin{array}{c}\text { Exposed to } \\
\text { parasitoid }\end{array}$ & $\begin{array}{c}\text { Negative } \\
\text { control }\end{array}$ \\
\hline S. litura & $92 \pm 6.2(6)$ & $0 \pm 0(6)$ & $74 \pm 10.6(6)$ & & $1.2 \pm 0.48(6)$ & $2.0 \pm 1.15(3)$ \\
H. armigera & $82 \pm 6.5(8)$ & $0 \pm 0(8)$ & $65 \pm 6.4(7)$ & $0.5 \pm 0.33(8)$ & $0.3 \pm 0.25(6)$ \\
\hline
\end{tabular}

${ }^{1}$ Percent parasitism = larvae with evidence of parasitism from rearing or dissection / number of larvae reared or dissected (excluding unexplained deaths) $\times 100$.

Non-target attack occurred in the first 20 minutes of non-target exposure (B1 and B2), with only one exception (Fig. 1), suggesting that the parasitoids' response to these species was in some way a central excitatory state caused by immediate prior contact with the target host (Withers \& Mansfield 2005). This priming could result in false positive results (i.e. parasitoids attacking hosts they would not normally attack), potentially removing a valuable biological control agent from contention (Coombs 2004). However, host attack is not evidence of impact on the host unless parasitoid offspring are produced, or host fitness is reduced (Van Driesche \& Murray 2004). No evidence of successful non-target parasitism was found, and exposure to parasitoids did not significantly increase the mortality rate of larvae in this study ( $S$. litura: $\mathrm{P}=0.596$, H. armigera: $\mathrm{P}=0.911$, Table 1$)$.

Arguments against the use of sequential no-choice tests centre on the risk of obtaining false negative results (Withers \& Mansfield 2005). These can occur if the period of access to non-target hosts is not long enough to allow time dependent changes in parasitoid responsiveness to become apparent (Barton Browne \& Withers 2002). In the current experiments, both non-target species were attacked early in the $24 \mathrm{~h}$ period of non-target exposure when observations were being made. This design therefore maximised the chance of non-target attack, as advocated by Withers \& Mansfield (2005). The addition of a positive control, effectively A-A-A, at the same durations as A-B-A, would be beneficial to confirm that the durations chosen are appropriate for the normal host attack behaviour of $C$. urabae (Withers \& Mansfield 2005). The addition of one positive control test for each non-target host species would minimise the need for extra parasitoids, hosts and observation time to conduct these tests.

The non-target attacks observed here permitted testing of the physiological ability of $C$. urabae to develop in S. litura and H. armigera, which is the ultimate test of host suitability, but is often difficult to test in endoparasitoids (Withers \& Barton Browne 2004; Barratt et al. 2007). Therefore the host range testing methodology proposed here was successful for testing C. urabae and will be used against the remainder of the proposed non-target species. The suitability of the duration of the exposure will be further confirmed with positive controls and would remain the same across different non-target hosts. If 
a similar response can be demonstrated for D. eucalypti, the other potential biological control agent against $U$. lugens, then the method proposed here will also be used for that species, with exposure durations adjusted according to its host attack behaviour.

\section{ACKNOWLEDGEMENTS}

Thanks to Andrea Sharpe, Diane Jones, Dave Hayes for laboratory assistance, and Richard Hill, Barbara Barratt and Mark Kimberley for advice. Funding was from FRST (contract C04X0302), Forest Industry Development Agenda (FIDA) and MAF.

\section{REFERENCES}

Allen GR 1990. Influence of host behaviour and host size on the success of oviposition of Cotesia urabae and Dolichogenidea eucalypti (Hymenoptera: Braconidae). Journal of Insect Behaviour 3(6): 733-749.

Barratt BIP 2004. Microctonus parasitoids and New Zealand weevils: comparing laboratory estimates of host ranges to realized host ranges. In: Van Dreische R, Reardon R ed. Assessing host ranges of parasitoids and predators used for classical biological control: a guide to best practice. United States Forest Service Publication, USA. Pp. 103-120.

Barratt BIP, Berndt LA, Dodd SL, Ferguson CM, Hill RH, Kean JM, Teulon DAJ, Withers TM 2007. BIREA - Biocontrol Information Resource for ERMA New Zealand Applicants. www.b3nz.org/birea/ (accessed 9 May 2007).

Barton Browne L, Withers TM 2002. Time-dependent changes in the host-acceptance threshold of insects: Implications for host specificity testing of candidate biological control agents. Biocontrol Science and Technology 12: 677-693.

Berndt LA 2007. Uraba lugens biological control progressing nicely. Forest Health News 169: 1.

Coombs M 2004. Estimating the host range of the tachinid Trichopoda giacomellii, introduced into Australia for biological control of the green vegetable bug. In: Van Dreische R, Reardon R ed. Assessing host ranges of parasitoids and predators used for classical biological control: a guide to best practice. United States Forest Service Publication, USA. Pp. 143-151.

Mansfield S, Watson MC, Kriticos DJ, Potter KJB 2005. Uraba lugens (Nolidae) biological control studies 2004/2005. Contract Report for Ministry of Agriculture and Forestry Biosecurity Authority. Ensis, Rotorua, New Zealand. 22 pp.

Van Driesche RG, Murray TJ 2004. Overview of testing schemes and designs used to estimate host ranges. In: Van Dreische R, Reardon R ed. Assessing host ranges of parasitoids and predators used for classical biological control: a guide to best practice. United States Forest Service Publication, USA. Pp. 68-89.

Withers TM 2003. The potential for biological control of Uraba lugens (Nolidae). Contract Report for Ministry of Agriculture and Forestry Biosecurity Authority, NZ Forest Research Institute, Rotorua, New Zealand. 20 pp.

Withers TM, Barton Browne L 2004. Behavioural and physiological processes affecting outcomes of host range testing. In: Van Dreische R, Reardon R ed. Assessing host ranges of parasitoids and predators used for classical biological control: a guide to best practice. United States Forest Service Publication, USA. Pp. 103-120.

Withers TM, Mansfield S 2005. Choice or no-choice tests? Effects of experimental design on the expression of host range. In: Hoddle MS ed. Second International Symposium on Biological Control of Arthropods. USDA Forest Service Bulletin, Morgantown, West Virginia, USA. Pp. 620-633. 